\title{
Fotografias post mortem entre imigrantes pomeranos
}

\section{Resumo}

\author{
Autor: Cristiano Gehrke \\ Doutorando Memória Social e Patrimônio Cultural \\ Universidade Federal de Pelotas (UFPEL) \\ Universidad de Buenos Aires (UBA) \\ cristianogehrke@gmail.com
}

O presente trabalho tem como objetivo analisar um grupo de fotografias que faz parte do acervo do Museu da Imigração Pomerana de São Lourenço do Sul/RS, que retratam pessoas já falecidas. Representando algo que nos provoca ao mesmo tempo repulsa e fascinação, este tipo de registro era uma situação tornada bastante comum em determinadas regiões do país devido à frequência da morte prematura de crianças ou adultos e a impossibilidade de produção de retratos destes, quando em vida. Além disso, existia até o início do século XX uma espécie de positivação da morte, uma vez que esta era compreendia como uma passagem para o encontro definitivo com Deus e assim, a produção de registros fotográficos seria uma forma de consolo aos familiares. Deste modo, pretende-se analisar o processo de elaboração de tais retratos, as motivações de sua produção, bem como as utilizações posteriores que estes registros tiveram ao longo dos anos.

\section{Palavras-chave}

Fotografia - Morte - Pomeranos

\section{Introdução}

Inserido dentro de um estudo mais amplo, no qual nos propomos a analisar o cotidiano de imigrantes de diferentes origens étnicas estabelecidos na Serra dos Tapes, no sul do estado do Rio Grande do Sul, este ensaio se propõe a analisar quais as possíveis motivações que levaram a produção de retratos post mortem, ou seja, retratos de pessoas já falecidas, em uma comunidade de imigrantes de origem pomerana, localizada no município de São Lourenço do Sul. Tais registros fazem parte do acervo do Museu da Imigração Pomerana e foram doações feitas pela comunidade tão logo inaugurado o museu.

A justificativa para a realização deste estudo, decorre pelo total ineditismo do tema, bem como da grande importância que tais registros imagéticos possuem. Visando descortinar um importante capítulo da história do imaginário deste grupo de imigrantes e de seus descendentes, que esteve sob o véu do esquecimento da historiografia até o presente momento, nos propomos a analisar alguns destes registros. 
Procuramos assim, esclarecer as motivações da produção deste tipo de retratos e desta forma desmistificar este tipo de imagem, que geralmente está cercado de uma vasta gama de sensações.

Para tanto, buscou-se, apoiado em uma série de textos, fazer um apanhado geral sobre as diferentes correntes teóricas que objetivam utilizar a fotografia como fonte para produção do conhecimento histórico, e, assim, pontuar aquela que será utilizada neste, para atingir os resultados propostos.

Foram feitas ainda, pesquisas em outras fontes, tais como os registros de batizados, casamentos e falecimentos na tentativa de datar os registros fotográficos ou identificar os personagens representados nas fotografias analisadas. Foram consultadas ainda entrevistas que fazem parte do acervo de história oral coletados durante a realização da investigação de doutoramento do presente autor.

\section{Fotografia, memória e morte}

Desde quando surgiu, no início do século XIX, a fotografia foi alvo de uma série de questionamentos e inúmeros foram os debates que ocorreram, tendo como foco central as discussões relacionadas a sua representação. Analisando a literatura especializada existente, percebemos que inúmeras são as correntes teóricas que procuram conceituar o termo fotografia (BORGES, 2003).

Melhor inserida no contexto a ser trabalhado é a definição que o antropólogo francês Joel Candau faz. Para ele, as fotografias são signos memoriais que podem servir para veicular informações, ativar lembranças sobre acontecimentos ou até mesmo afirmar o caráter durável de um laço familiar (CANDAU, 2011, p. 117). A sua utilização propicia, ainda, o desencadeamento de lembranças de fatos passados, já adormecidos, e lhe confere papel fundamental na reconstrução histórica (MARCONDES, 2007).

Neste sentido, a vontade familiar de manter a memória do corpo doméstico e, com isso, sua identidade, fez com que a fotografia conseguisse tal status na sociedade, o status de desencadear lembranças. De acordo com Candau (2011, p.118), a sua invenção favoreceu a construção e manutenção da memória de certos dados factuais, de acontecimentos históricos, de catástrofes, mas também de fatos familiares, fornecendo simultaneamente a possibilidade de manipulação dessa memória.

Pelo fato de permitir a conservação visual do passado desencadeando recordações, e possibilitando, desse modo, diferentes interpretações (SOARES, 2007), a fotografia 
pode ser considerada uma fonte de pesquisa completa, uma vez que as suas possibilidades de estudo são multiplicadas. Seu papel mais importante como método de observação não é apenas expor aquilo que é visível, mas, sobretudo, tornar visível o que nem sempre é visto (GURAN, 2002, p. 4).

Podemos assim conceituar a fotografia como sendo a própria cristalização da cena, o registro de um dado fragmento selecionado do real, congelado num determinado momento de sua ocorrência, ou seja, um recorte espacial, interrompido temporalmente, fixado num suporte material (KOSSOY, 2009, p. 29).

Uma cena gravada, que jamais se repetirá. O momento vivido, congelado pelo registro fotográfico, é irreversível. As personagens retratadas envelhecem e morrem, os cenários se modificam, se transfiguram e também desaparecem (KOSSOY, 2009, p. 139) - ou como afirma Roland Barthes, aquilo que a fotografia reproduz, só aconteceu uma vez: ela repete mecanicamente, o que nunca mais poderá repetir-se existencialmente (BARTHES, 2009, p. 12).

Porém, assim como as outras fontes, os documentos fotográficos também são plenos de ambiguidades, portadores de significados não explícitos e de omissões pensadas, calculadas (KOSSOY, 2009, p. 22). Ana Maria Mauad afirma que a imagem não fala por si só; é necessário que as perguntas sejam feitas. Não importa se a imagem mente; o importante é saber por que e como mentiu (MAUAD, 1990), ou, como afirma Susan Sontag: "mesmo que uma foto possa distorcer algo, sempre existe o pressuposto de que algo existiu ou existe, e era semelhante ao que está na imagem" (SONTAG, 2004, p. 16).

As fotografias condicionam com grande intensidade a memória dos fenômenos pretéritos, por constituírem um registro visual dos mesmos. A fotografia é seletiva tal como a memória. Ao jogar o enquadramento sobre um pedaço do real, o que fíca no interior deste é tido como memória, confundindo-se com o próprio passado, enquanto o que ficou de fora poderia ser concebido como o esquecimento, e, por isso, não mais levado em conta (POSSAMAI, 2005, p.142).

Levando com consideração os aspectos apontados anteriormente, faremos em seguida uma breve explanação sobre algumas características e elementos comuns em registros fotográficos post mortem.

\section{Fotografia e morte}


Os registros de pessoas já falecidas, principalmente de crianças, eram bastante comuns no século XIX e início do século XX. Estas fotografias de modo geral tinham como objetivo fazer parecer que o indivíduo não estivesse morto, sendo assim, os mesmos, em alguns dos casos eram retratados com os olhos abertos. Para Maria Elisa Linhares Borges, isto acontecia não apenas por ocasião da produção do retrato, mas era a forma como o indivíduo era enterrado. Segundo a autora, as "crianças eram consideradas anjinhos 1 ", e não estavam "acostumadas com as coisas da vida, e quase não conheciam as coisas de Deus", sendo assim, enterrá-las de olhos abertos seria a única forma de estas encontrarem o caminho do céu, pois, com os olhos fechados, elas "andariam a esmo no limbo, sem nunca encontrar a casa do Senhor" (BORGES, 2003, p.65).

Ainda segundo a autora, para os familiares, com os olhos abertos do bebê recémmorto, a fotografia funcionaria como prova de que a criança partiu preparada para a sua longa viagem em direção ao paraíso (BORGES, 2003).

Em relação à coloração das roupas, temos a predominância do branco, que era a cor mais utilizada neste tipo de evento. Esta cor não apenas estava presente nas roupas, mas em outros elementos do funeral, tais como as flores e o caixão. Para Vailati (2011), os compêndios de semiologia cristã nos informam ser esta cor, o símbolo da alegria e, antes de tudo, da inocência e da pureza virginal. Como a cor da alegria, o branco do hábito mortuário infantil se opõe à mortalha do adulto, muitas vezes de cor preta ou roxa, as cores da penitência. George Ferguson se referindo à cor branca, no cristianismo, afirma que "white has always been accepted as symbolic of innocence of soul, of purity, and

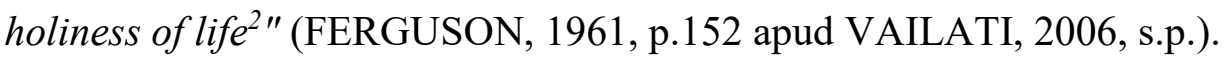

Dentre o acervo fotográfico do Museu da Imigração Pomerana, são quatro os registros fotográficos de pessoas falecidas. A pouca representatividade desta categoria, pode ter uma série de significados. Entre outros fatores, podemos destacar os seguintes: as dificuldades de acesso a um fotógrafo, devido a grande distância entre núcleo rural e o centro da cidade de São Lourenço do Sul, onde se localizavam os estúdios fotográficos; os altos custos que tal procedimento traria às famílias, que contavam com um limitado orçamento familiar.

\footnotetext{
${ }^{1}$ Vale destacar que o termo "anjinho" é utilizado para designar a criança morta.

${ }^{2}$ Conforme tradução do autor: "branco sempre foi aceito como símbolo de inocência de alma, de pureza e santidade de vida".
} 
Representando algo que nos provoca ao mesmo tempo repulsa e fascinação, fotografias de pessoas/crianças mortas eram uma situação bastante comum em determinadas regiões do país, devido à frequência da morte prematura destas, ocasionada por uma série de motivos. Entre estes, a dificuldade de acesso a atendimento médico que enfrentavam os habitantes dos núcleos coloniais, a falta de médicos especializados, a inexistência ou não-obrigatoriedade da vacinação infantil.

Luiz Lima Vailati trata deste tema em sua tese de doutoramento, em que afirma que era dada uma grande importância aos funerais infantis, o que decorria de uma espécie de crença da "positividade da morte infantil", ou seja, morrer ainda criança era uma garantia de salvação. E, ainda, a morte de uma criança, para uma família, era um sinal de que esta, teria alguém intercedendo a seu favor junto "às autoridades celestes" (VAILATI, 2005).

Para a historiadora Ana Maria Mauad, fotografias de pessoas mortas, inclusive de crianças, não eram raras nos álbuns familiares (MAUAD, 1999). Quando a morte chegava, muitas famílias percebiam que não haviam tido tempo para captar a imagem do ser amado que estava para desaparecer. Por este motivo, mesmo sem vida, o corpo deveria ser fotografado (SOARES, 2007, p. 79), de sorte que esta seria a única e última oportunidade de acrescentar à memória familiar a imagem dos que partiram prematuramente. Deste modo, o funeral era a última oportunidade para o indivíduo ser fotografado (VAILATI, 2006).

Esta fotografia era o único meio de eternizar a condição humana, o único registro material da existência da criança e uma espécie de indicativo do apreço pela mesma, pois, "providenciar certidões de nascimento e falecimento envolvia uma série de entraves burocráticos, bem como um alto custo, principalmente para as populações rurais" (SOARES, 2007, p. 80).

Dentre as motivações da produção destes retratos, temos ainda a necessidade de preservar a memória do filho morto, através de um artefato que ajudava os pais a enfrentarem o luto, e que representava não só a imagem, mas os significados mais bonitos da breve existência daquele ser amado. Podia representar até mesmo a vontade, mesmo que inconsciente, de trazer à vida a pessoa que acabou de morrer, funcionando quiçá como uma espécie de negação do fim, uma forma de prolongar a vida (SOARES, 2007, p.13, 86 e 104).

Na maioria das vezes, de acordo com Vailati (2006), a fotografia do "anjinho" não apenas recordava um evento que era fundamental na afirmação da família perante a 
sociedade (cujo investimento material e simbólico tinha papel estratégico nisso). Mais que isso, permitia também o exercício da celebração da unidade familiar, ao registrar um acontecimento cuja periodicidade dá lugar aos reencontros que reforçam a identidade da comunidade de sangue.

No que se refere às funções das fotografias de crianças mortas, Vailati destaca que:

\footnotetext{
ao servir de paliativo - tanto para sua ausência como, mais especificamente, para o problema de não ter podido ser fotografada em vida -, prestou-se, com efeito, a fornecer a representação imagética desta, para a lembrança dos seus parentes próximos, bem como para o conhecimento dos membros familiares espacial ou temporalmente distantes (VAILATI, 2006, s.p.).
}

Assim percebemos que, como único registro, ou ao menos o último, daquele que prematuramente partira, alguns aspectos nesta representação fotográfica tinham grande importância: por exemplo, a preparação do cadáver, a escolha da posição em que era fotografado e demais cuidados que tinham como objetivo "guardar a imagem do falecido de forma mais próxima de quando este vivia, contornando, desta forma, a transformação que a morte já se encarregara de iniciar" (VAILATI, 2005). 


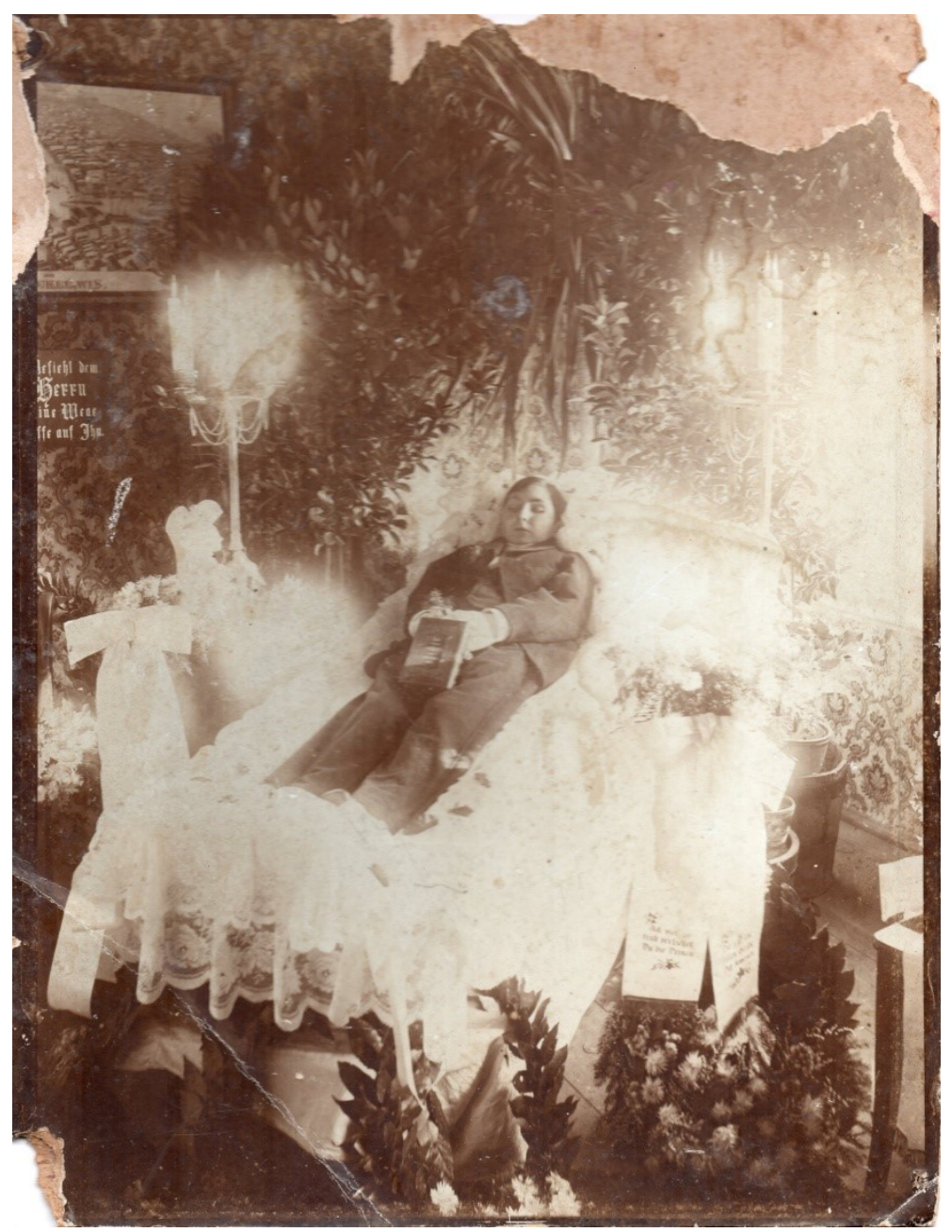

Figura: Velório de um jovem rapaz não identificado ( $\mathrm{N}^{\circ}$ Inventário CH108). Fonte: Acervo Museu da Imigração Pomerana 


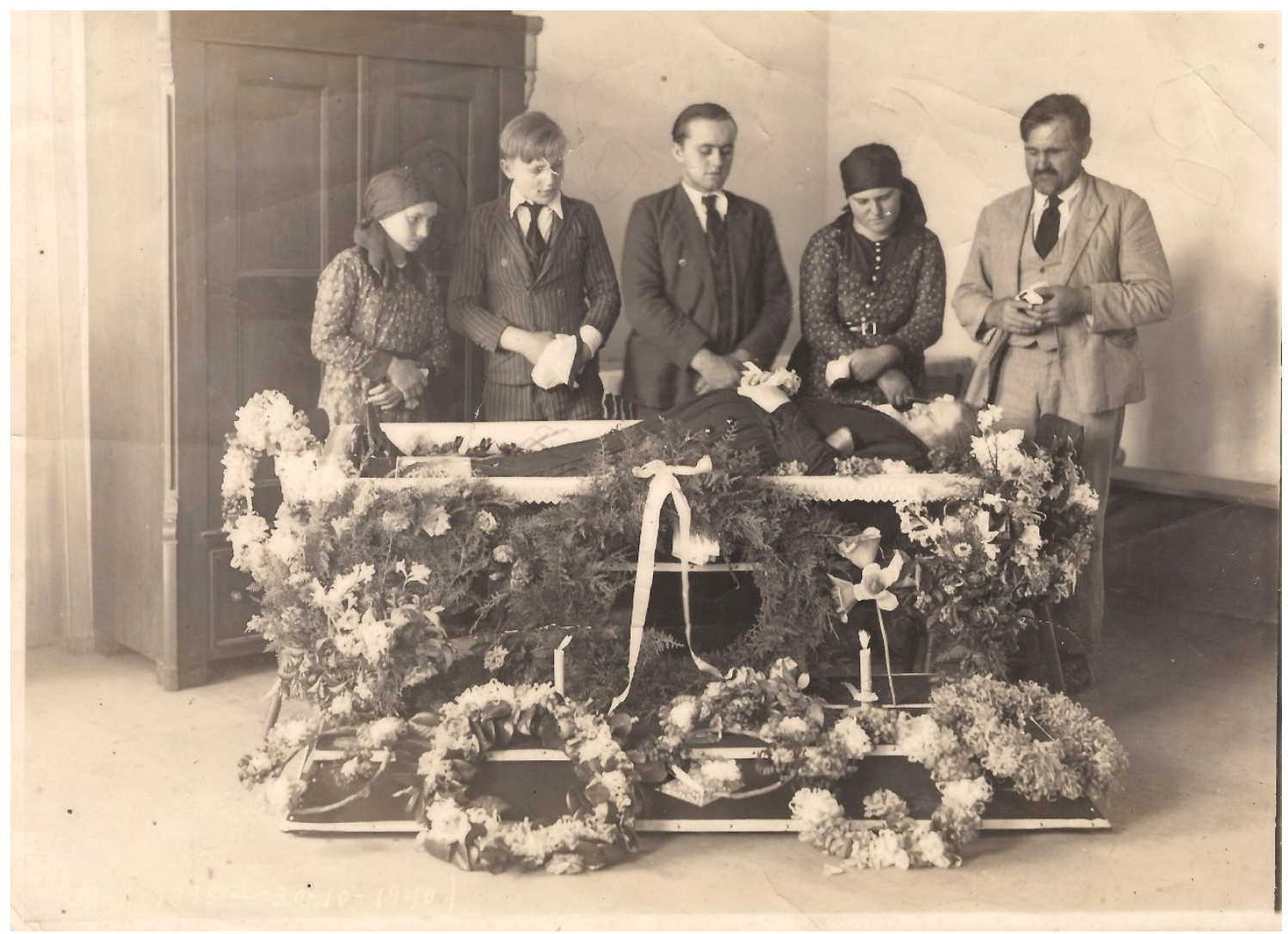

Figura: Velório de uma senhora não identificada ( ${ }^{\circ}$ Inventário CH222).

Fonte: Acervo Museu da Imigração Pomerana

\section{Algumas considerações}

Em se tratando de descendentes de imigrantes pomeranos, a religiosidade era uma característica importante, de modo que a devoção aos mortos assumia um especial valor. Para eles, existia a necessidade de realização de cultos que assegurassem que o morto atingiria o paraíso. Outros procedimentos se faziam necessários: acendiam-se velas, colocavam-se flores. Enfim, existia toda uma simbologia que servia como uma espécie de atestado para os vivos de que a alma do morto estava bem encaminhada.

Desta forma, a produção de retratos de pessoas já falecidas pode ser classificada como um certificado de que a passagem até o caminho dos céus tenha sido feita com sucesso, baseado em símbolos e aspectos que devem ser respeitados, no momento da produção de um retrato deste gênero.

A pessoa que falecia podia esperar sobreviver apenas na memória de amigos, familiares. Assim, a imagem de uma pessoa morta possuía uma função memorial, que nascia no momento em que um olhar saudoso repousava sobre ela. O desejo de lembrança 
e de conforto, no trabalho de luto, somado à religiosidade, fez com que os usos e funções da imagem tivessem o poder de representação, de tornar presente o ausente, de servir como objeto de culto e adoração, de confirmar que a pessoa realmente existiu (SOARES, 2007, p.68).

Atualmente esta prática entrou em desuso, devido a uma série de fatores, dentre os quais podemos destacar a facilidade de acesso a máquinas fotográficas e a grande quantidade de fotografias diárias produzidas, além do barateamento de todo o processo, o que permite que sejam produzidas muitas fotografias do indivíduo ainda em vida.

Conforme exposto acima, mesmo com uma série de dificuldades para produção de retratos na comunidade estudada, estes foram realizados e os registros sobreviveram ao tempo e foram incorporado à coleção do Museu da Imigração Pomerana, cumprindo assim o papel para o qual foram concebidas, ou seja, perpetuar a existência dos indivíduos nela retratos.

\section{Referências}

BARTHES, Roland. A câmara clara. Edições 70: Lisboa, 2009.

BORGES, Maria Elisa Linhares. História e fotografia. Belo Horizonte: Autêntica, 2003.

CANDAU, Joel. Memória e identidade. São Paulo: Ed. Contexto, 2011.

DUBOIS, Philippe. O ato fotográfico e outros ensaios. Papirus Editora: Campinas, 2010.

GEHRKE, Cristiano. Fotografia e musealização da história da imigração italiana: sistematização do acervo fotográfico do Museu Etnográfico da Colônia Maciel.

Trabalho de Conclusão de Curso de licenciatura em História. UFPEL: Pelotas, 2010. KOSSOY, Boris. Realidades e ficções na trama fotográfica. São Paulo: Ateliê Editorial, 2009.

MARCONDES, Marli. Conservação e preservação de coleções fotográficas.

Disponível em:

http://www.historica.arquivoestado.sp.gov.br/materias/anteriores/edicao01/materia02/, acessado em 13 de abril de 2007.

MARTINS, José de Souza. Sociologia da fotografia e da imagem. São Paulo: Contexto Editora, 2011.

MAUAD, A. M. Sob o signo da imagem: a produção da fotografia e o controle dos códigos de representação social pela classe dominante no Rio de Janeiro, na primeira 
metade do século XX. Tese (Doutorado em História) - Programa de Pós-Graduação em História Social, Universidade Federal Fluminense, Rio de Janeiro, 1990.

SOARES, Miguel Augusto Pinto. Representações da morte: fotografia e memória. Dissertação de Mestrado em História. PUC-RS. Porto Alegre, 2007.

SONTAG, Suzan. Sobre fotografia. Companhia das Letras: São Paulo, 2004.

VAILATI, Luiz Lima. As fotografias de "anjos" no Brasil do século XIX. An. Mus.

paul. v.14 n.2 São Paulo jul./dez. 2006. Disponível em:

http://www.scielo.br/scielo.php?script=sci_arttext\&pid=S0101-

$47142006000200003 \& \operatorname{lng}=$ pt\&nrm=iso\&tlng=pt, acessado em 28/12/2011.

VAILATI, Luiz Lima. A morte menina: práticas e representações da morte infantil no Brasil dos oitocentos (Rio de Janeiro e São Paulo).Tese (Doutorado em História Social) - Faculdade de Filosofia Letras e Ciências Humanas, Universidade de São Paulo, São Paulo, 2005. 